\title{
Unmet Need for Sexuality Education among Adolescent Girls in Southwest Nigeria: A Qualitative Analysis
}

\author{
Olayinka O Omigbodun ${ }^{1}$ and Akinyinka O Omigbodun ${ }^{2}$
}

\begin{abstract}
This study utilises a qualitative approach to elicit the reproductive health concerns of girls at a Christian summer camp with a view to making recommendations on how to improve the content and process of future sessions. The girls asked questions anonymously about various aspects of their sexuality, which were analysed to identify emergent themes. There were 75 participants with ages ranging from childhood to late adolescence (7-21 years). The different levels of cognitive development are clearly illustrated in the types of questions asked. The late adolescents focused on coping with relationships and demands for sex. The early and middle adolescents focused on their feelings, relationships, menstruation and breast size. Those in childhood (7-11 years) appeared totally ignorant about parts of their body. Myths and misconceptions were identified in all age groups. Future sessions should address the peculiar needs of these different age groups. Christian and other religious groups should work with health educators to develop realistic teaching guidelines that focus on the everyday concerns of the youth. (AfrJ Reprod Health 2004; 8[3]:27-37)
\end{abstract}

\section{RÉSUMÉ}

Besoin non-satisfait de l'éducation sexuelle chez les adolescentes au Sud du Nigéria. Cette étude se sert d'une approche qualitative pour jeter la lumière sur les soucis des filles dans un camp chrétien d'été par rapport à leur santé de reproduction dans le but de faire des recommandations sur la manière d'améliorer le contenu et le procès des futures sessions. Les filles ont posé des questions de façon anonyme sur les aspects différents de leur sexualité qui ont été analysées pour identifier les thèmes émergeants. Il y avait 75 participants dont l'âge variaient de l'enfance jusqu'en premise de l'âge adulte (7-21 ans). Les niveaux différents du développement cognitif sont clairement illustrés à travers les genres de questions qu'elles ont posées. Les adolescents en prise de l'âge adulte ont concentré sur la manière de se débrouiller avec des rapports et des exigences du sexe. Celles de la prime et de la moyenne adolescence ont concentré sur leurs sentiments, les rapports, la menstruation et la taille des Seins. Celles qui étaient encore dans l'enfance (7-11) paraissaient totalement ignorer les parties de leurs corps. Chez tous les groupes d'âge, on a reconnu des mythes et des superstitions. Les futures sessions doivent s'occuper des besoins des différents groupes religieux, travaillent ensemble avec les éducateurs en matière de santé pour élaborer des guides pédagogiques qui mettront l'accent sur les affaires de la jeunesse. (Rev Afr Santé Reprod 2004 8[3]:27-37)

KEY WORDS: Qualitative analysis, adolescent girls, sexuality, Christian, Nigeria

${ }^{1}$ Senior Lecturer in Psychiatry, ${ }^{2}$ Professor of Obstetrics \& Gynaecology, College of Medicine, University of Ibadan, Ibadan, Nigeria.

Correspondence: Dr Olayinka Omigbodun, Department of Psychiatry, College of Medicine, University College Hospital, Ibadan, Nigeria.E-mail4yinkas@skannet.com 


\section{Introduction}

The importance of reproductive health education for children and adolescents is now well established. With increases in teenage sexually transmitted diseases and the human immune deficiency/acquired immune deficiency syndrome (HIV/AIDS) pandemic, there is an increasing focus on reproductive education for this critical age group. There has been a recent radical and widespread change in public opinion about the need for sex education, now described as family life or reproductive health education. ${ }^{1}$

Despite this, there still remain a few frightened adults who will continue to encourage a culture of silence. A recent newspaper report points to this:

\section{The Project for Human Development, a Lagos- based NGO, has criticised in very strong terms the federal government's decision to introduce sex education in primary and secondary schools across the country. The (executive director) said its introduction will destroy the latency period and innocence of young children. He further said that education in sexuality lies with the parents of the child because every child is unique, and it is therefore left for the parents to know when and how to pass such information.}

While it is true that every child is unique, several studies reveal that many parents in our culture are silent about sexual issues. ${ }^{3}$ Furthermore, what happens when the parents do not have the necessary knowledge and have also been operating based on myths and misinformation? Should children be left to bear the brunt of their parents' ignorance? This is where religious institutions and schools can come in to assist.

Several years ago, having sex education sessions within churches may have been unheard of. ${ }^{4}$ Now churches and other religious organisations are calling for sex education for their youth. ${ }^{5,6}$ The involvement of churches and other religious organisations in educating the youth about sexuality and in the fight against sexually transmitted infections (STIs) must be actively encouraged. In many societies, these religious organisations are meeting places for youth of diverse backgrounds and cultures. Moreover, the positive influence of church membership and attendance on the reproductive health of youths is now well-established.,

It is important for family health and/or reproductive health educators to realise that they cannot work in isolation from religious groups. In several countries, church policy influences how and what is taught about sexuality. ${ }^{9,10}$ If adolescents are taught things that are at variance with what they are taught within their religious groups, then more confusion will arise. On the other hand, it is important for churches to have well organised programmes integrating religious views with sex education based on socio-biological facts and findings.

In working with churches and other religious organisations providing education, it is important to identify the concerns of the youth within these groups and to determine the process and content needs of planned programmes. Is it appropriate to have sessions with all adolescents or should they be divided according to age group? If they are to be divided, what age groups should be together? Also what are the concerns of girls within this Christian setting that require identification? What myths and areas of ignorance need to be tackled?

Qualitative research has been found to be 
very useful for the study of sensitive issues such as sexuality within different sociocultural groups because it allows for the discovery of unexpected issues and topics, which would not have been visible if a fixed design or questionnaire were used. ${ }^{11}$ The study reported here adopts a qualitative approach to study the reproductive health concerns of girls at a Christian summer camp, with a view to making recommendations on how to improve the process and content of future reproductive health sessions.

\section{Methods}

OO was invited to give a talk on reproductive health at a Christian camp organised for young girls by the Anglican Church. OO gave a title to the talk based on a scripture from the Bible (Psalm 139, verse 14): "I will praise thee; for I am fearfully and wonderfully made: marvellous are thy works; and that my soul knoweth right well." The talk touched on the key parts of the woman's sexual organs, care of the breasts, genitals and the menstrual cycle. The lecture also explored the subjects of STIs and HIV/AIDS.

At the beginning of the talk, sheets of paper and pens were distributed to all the girls who were all seated in a big hall. They were told to write their ages and secular school class on top of their sheets of paper. Their names were not to be written on the sheets. A big flip chart was also present to help illustrate these points. After each segment of the talk, the girls were told to write down all the questions and worries they had about that topic. Enough time was made available and all teachers and chaperones were kept away from the girls while they were writing down the questions. It was stressed again that no names were required and no one would be identified. At the end of the talk, all the sheets of paper were collected from the girls. They were quickly sorted out into groups and the questions were answered. The girls were given the option of writing out questions in their native language, although only two girls took up this option.

\section{Analysis}

The statements and questions written down by the girls were analysed using interpretative phenomenological analysis. ${ }^{12}$ The girls were divided into five age groups: 7-11, 12-13, 14$15,16-17$ and $18-21$ years respectively. The questions written down by the girls were read repeatedly and then coded to identify emergent themes. Recurrent themes were then identified across board. OO carried out the principal analysis. AO also read the questions independently. The emergent and recurrent themes were then discussed and agreed upon.

\section{Results}

There were 75 participants at the session. Six $(8 \%)$ of them did not indicate their ages or classes. Table 1 reveals the ages and classes of 69 participants who provided full information. The age range was 7-21 years with a mean age of 13.59 years (SD 3.39). Most of the 7-11-year-olds were still in primary school. However, a large number of them were also found in higher classes such as JSS 2 (five pupils) and JSS 3 (one pupil). Among the 10 girls in primary schools, there 
was no particular pattern of age placement in classes. Of the four 8-year-olds, one was in primary three, two in primary four and the last in primary six. The two 7-year-olds were in primary classes three and one respectively. All but two of those out of school were awaiting results and seeking admission into higher institutions. One of these was a 16year-old who had completed secondary school two years earlier. Two students were
Girls aged 18-21 years tended to ask about how to cope with relationships and demands for sex as well as issues relating to their menstruation. The recurrent themes from their questions are shown in Textbox 1.

The 16-17-year-olds asked questions on how to manage the demands of menstruation, breast size and issues of sexual intercourse during menstruation. The recurrent themes are demonstrated in

Table 1 Ages and Classes of the Participants

\begin{tabular}{lrrrrrr}
\hline Class & $7-11$ & $12-13$ & $\begin{array}{r}\text { Age (years) } \\
14-15\end{array}$ & $16-17$ & $18-21$ & Total (\%) \\
\hline Primary (grades 1-6) & 10 & - & - & & - & $10(14.5)$ \\
JSS1 (grade 7) & 6 & - & 1 & - & - & $7(10.2)$ \\
JSS2 (grade 8) & 5 & 3 & - & - & - & $8(11.6)$ \\
JSS3 (grade 9) & 1 & 4 & 4 & - & - & $9(13.0)$ \\
SSS (grades 10-12) & & 3 & 11 & 11 & 1 & $26(37.7)$ \\
Completed secondary school & & & & 2 & 7 & $9(13.0)$ \\
Total (\%) & $22(31.9)$ & $10(14.5)$ & $16(23.2)$ & $13(18.8)$ & $8(11.6)$ & $69(100.0)$ \\
\hline
\end{tabular}

already in higher institutions.

They all lived in towns in the southwest of Nigeria except two who were based in the southeast region. There were 19 from Ibadan municipality, nine from Oyo town, five from Ogbomosho and the remainder were from Ekiti, Okitipupa, Abeokuta, Lagos, Ilorin, Ife, Ilesha, Ondo, Ijebu, Onitsha and Owerri. Age-RelatedQuestions
Textbox 2. The emergent and recurrent themes among the 14-15-year-olds are illustrated by the variety of questions they asked about their feelings, relationships, breasts and menstruation, and these are summarised in Textbox 3.

The 12-13-year-olds were also bothered about relationships, menstruation, breasts and pregnancy. Their concerns are illustrated in Textbox 4. 


\section{Coping with Relationships}

At what age can a girl have a boyfriend?

What if your boyfriend demands for sex and when you refuse he says he will leave you? Should you leave the boy?

- How do we know that a boy is a virgin?

\section{Menstruation}

- During menstruation, I am afraid to take any drug because I believe the blood will rush out. Please enlighten.

- I have been made to believe that menstrual pain is due to the clotting of blood in the uterus and that the clot can be dissolved by drinking hot water. Is this right and healthy?

- What drug or medication can I use for serious menstrual pain?

\section{Textbox 1 Questions Asked by Girls Aged 18-21 Years}

\section{Menstruation}

- What is responsible for the pain I feel during my monthly period?

- What happens when the menstrual flow becomes black or brown and how can we prevent it?

. Is it good to use a cloth during menstruation?

- What kind of cloth can we use during menstruation?

- What causes irregular menstruation after three years of starting it?

. Is it true that if you use toilet roll when menstruating you will have disease?

- How many days should the menstrual flow last for?

- Is it true that if a girl has sex while menstruating she will give birth to an albino child?

- What kinds of food should we eat during menstruation?

\section{Breast Size}

- A friend of mine is 17 years old, has sickle cell disease and has no breasts. She says this is because she does not have sufficient blood. Is this true and what can she do?

- There is a 17-year-old girl in my class with no breasts. What will happen to her and what can she do?

Textbox 2 Questions Asked by Girls Aged 16-17 Years 
Feelings

Why do we feel shy when we are lectured on these topics?

Relationships

Is it a sin to have a boyfriend without any evil motive due to pressure from friends?

How do we know if a boy is a virgin? There is normally a test for girls.

At what age is it right to keep a boyfriend? Because a pastor's wife once said it is right at the age of 15 . Is this factual?

- Is it good to have boyfriends?

- If a man and woman sleep together without removing their clothes, will the lady get pregnant?

\section{Breasts}

When our breasts are paining us, what can we do?

Why is it that a girl of 17 will have no breast?

Menstruation

Is it true that tissue paper is not hygienic for the body.

If a girl has sexual intercourse during menstruation what will happen to the girl?

When menstruation comes unexpectedly at school what should we do?

When we start menstruating should we tell our parents?

Why do we have menstrual pain?

Why is it that on the second day of menstruation the blood smells?

\section{Textbox 3 Questions Asked by Girls Aged 14-15 Years}

\section{Relationships}

When is it right to have boyfriends?

What can we do when we have a crush on someone to avoid leading us to sin?

\section{Breast Size}

Some people say that if you wear a bra early your breast will be smaller.

Wearing a bra is a problem and could be quite uncomfortable. Some say that if you

wear a bra early, your breast will become smaller. Is that true?

- At what age are breasts supposed to come out?

\section{Menstruation}

When should a person start menstruating?

Does menstrual blood come out from the urethra or vagina?

\section{Pregnancy}

What forms the child in the stomach of the woman? Where does the baby come from?

What becomes pregnant in the body?

If a girl is raped by more than one person will she get pregnant?

If a girl who has not started menstruating has sex with a boy will she get pregnant?

Textbox 4 Questions Asked by Girls Aged 12-13 Years 
Questions from the 7-11-year-olds focussed mostly on the meanings of sexrelated body parts and concepts. The youngest members of this sub-group were more concerned about the functions of specific body parts, asking such questions as "What is our vagina?" "Where is our vagina?" "What is a womb?" and "What is menstruation?" The emergent themes are shown in Textbox 5 .

Menstruation was the one subject that seemed to be of concern across all the age groups attending the camp. Relationships with the opposite sex and concern about breast development and size were the other two issues that almost cut across all the groups, being present in four of the five groups. The issues of STIs and HIV/AIDS did not seem to elicit queries from the girls in spite of the time devoted to these topics during the talk. The only questions asked about HIV/AIDS were "What is the full meaning of HIV/AIDS?" from a 16-year-old in SS 1 and "Can one get HIV from sharing cutlery with an infected person?" from a 14-year-old SS I student. No questions were asked about other STIs.

\section{Menstruation}

How do young people know when menstruation starts?

What age does menstruation start?

Is it good for us to wear two pairs of pants during menstruation?

\section{Sexual Intercourse}

- What exactly is sex? My mates say sex is about a girl sleeping with a boy? (JS 3 girl)

- What happens to a girl's body when she is pregnant?

- How do women give birth to babies? Were the babies in their tummies since they were girls?

- What becomes pregnant in our body? Which place in our body carries the pregnancy?

- How many months does the pregnancy remain in the stomach?

- When a person is raped can they get pregnant?

How do people get pregnant?

Body Parts and Functions

What is the meaning of vagina? Where is our vagina? (A JS 2 girl)

At what age will our breasts grow?

What is the meaning of penis?

What is the meaning of menstruation?

If a girl is already 11 years old and does not have breasts, what is responsible? (A JS 2 girl)

Textbox 5 Questions Asked by Girls Aged 7-11 Years 


\section{Discussion}

This sample has girls with ages ranging from 7 to 21 years, reflecting childhood through early, middle and late adolescence. The changes in cognitive thinking and understanding of sexuality issues at these various stages should therefore be well reflected in this study population.

As is expected with increasing age, there is a higher secular school class. However, some interesting trends in our society are reflected in this sample. There is a general lack of standardisation of ages in schools. In countries like the USA and Britain, it is possible to have an idea of a child's school grade from his/her age. This is not the case in Nigeria. This has a lot of implications for the welfare of the child. Even if they can cope academically, the emotional and social skills largely depend on the age of the child. ${ }^{13}$ Also, trying to draw out reproductive health education programmes for use in various classes in schools may be problematic since children and adolescents at different levels of development and understanding will be present in each class.

The different levels of cognitive development are clearly illustrated in the process and content of the questions asked about sexuality. Those still in childhood (7-11 years) appeared totally ignorant about parts of their body and the terminologies used. They asked questions like 'What is our vagina?' 'Where is our vagina?' 'What is menstruation?' What exactly is sex?' This form of questioning is not surprising, for cognitive development at this stage begins to move from the concrete operations of children to the formal operations that mark adolescence. ${ }^{13,14}$ These children were still at the stage of concrete operations and could manipulate concrete objects but had difficulty conceptualising abstract ideas.

The 12-13-year-olds are at the stage of early adolescence and would have started to experience the bodily changes and feelings. This is reflected in the questions they asked. They were concerned about boyfriends and changes in their bodies. Formal operations emerge in early adolescence, at about the age of 11 years, and adolescents learn to evaluate their environment in less concrete ways. ${ }^{14}$ They develop increasing capacity to think logically, work with abstract ideas, predict consequences or behaviour, and speculate about future events. ${ }^{15}$ Some have described early adolescence as characterised by turmoil stemming from the physical changes of puberty and intense pre-occupation with physical appearance. This is reflected in the concerns expressed by this age group about breast size and the factors that may influence it: "Some people say that if you wear a bra early your breasts will be smaller. Is that true?"

According to Dell, ${ }^{16}$ middle adolescence focuses on self-identification and realisation. Girls are said to show more interest in developing intense loving relationships with boys. This is also reflected in some of the concerns expressed by the group of 14-15year-olds about their feelings and relationships: "Why do we feel shy when we are lectured on such topics?" Such intense concern about feelings and a sense of embarrassment or shyness when matters of relationship with the opposite gender or about the organs of reproduction were being discussed was only expressed by this group. 
Members of the group (together with the 1213-year-olds) also expressed concern about feelings of guilt when contemplating relationships with boys: "Is it a sin to have a boyfriend without any evil motive due to pressure from friends?" and "Is it good to have boyfriends?" The late adolescents also asked questions in regard to relationships and what to do about demands for sexual relationships, obviously in relationship to what they have been experiencing. At this stage it is expected that they will have a more integrated solid sense of self. ${ }^{16}$

The overall focus of the girls' questions was on relationships, managing menstruation, breast care and factors associated with pregnancy. From verbal interaction with the study participants, there appears to be a lot of information about safe sex, HIV/AIDS and STIs. This did not however feature prominently in their questions or expression of concern. It appears the girls were more concerned with their relationships and feminine functions. Could it be that when information about safe sex, STIs and HIV/AIDS is provided to adolescents, the people providing them with such information miss out education on pubertal changes, care of the breasts, menstrual hygiene and other foundational aspects of concern to these girls? It is possible that adolescent girls actually find it easier to relate to information on normal anatomical and physiological changes at puberty, since that is what they are already experiencing and coping with, rather than HIV/AIDS and STIs, which appeared distant to their reality. Or could this just be the feeling of invulnerability that pervades the period of adolescence? ${ }^{13}$
A lot of ignorance about body functioning was identified even among the late adolescents. The myths and misinformation identified is indicative of a lack of relevant reproductive health education for these adolescents and their peers in the communities they were drawn from. Some of the myths identified include: "Is it true that if a girl has sex while menstruating she will give birth to an albino child?"; "Some people say that if you wear a bra early, your breast will be smaller"; "Some people say that nipple pain is a sign of pregnancy"; "We have been made to believe that menstrual pain is due to clotting of blood in the uterus and that it can be dissolved by drinking hot water"; "Is it true that toilet tissue is not good when we are menstruating because it causes diseases?" The ignorance surrounding menstrual information was illustrated in another study in southwestern Nigeria, where it was found that $40 \%$ of menstruating girls were deficient in knowledge about menstruation, $66.3 \%$ of girls used unsuitable materials as menstrual absorbent and $84 \%$ were not prepared for their first menstrual flow. ${ }^{17}$ Studies in both developed $^{18}$ and developing countries ${ }^{19,20}$ have found a culture of silence and shame surrounding menstruation, with numerous taboos and restrictions on girls and women. These are issues that should be dealt with aggressively by health educators. There is a dearth of information about health to girls concerning care of the breast, breast size and choosing an appropriate brassiere. These are important and everyday concerns of girls that need to be addressed. 
The issue of relationships with the opposite sex was paramount among questions participants in this study asked. It is obvious that the girls need clear guidance on this very important aspect of functioning. Christian groups need to draw clear and realistic guidelines for these youths about how to conduct themselves in healthy relationships with members of the opposite sex.

While the findings from this study provide strong evidence of an unmet need for sexuality education in adolescents living in this part of the developing world, it is important to bear in mind that the group is a select one, limited to adherents of one faith or girls living with members of this particular religious organisation. Thus, it may not necessarily reflect the state of affairs in the wider population of adolescents in the area. The interpretation of the tenets of the faith by parents and guardians of the girls may have affected their ability to discuss issues of sexuality with their daughters and wards. In wanting the girls to abide by the teachings of the faith in expressing sexual behaviour, parents and guardians may be silent, or may provide incomplete or inaccurate information. This may have contributed to their level of awareness on sexuality and may have informed some of the myths and misconceptions they had. Whatever the limitations, the results demonstrate a need for sexuality education for young people living in the area.

\section{Conclusions}

This qualitative study identifies myths, ignorance and misconceptions in a group of adolescent girls attending a Christian summer camp. There is a need in this group of girls for education about the anatomical and physiological changes they should expect in their bodies as they grow through puberty and adolescence. This education has to be commenced in the pre-pubertal phase when the focus should be on explaining the structure and function of the various body parts and the changes to expect at puberty. In the older adolescents, the content and process of this education require modification to accommodate the shift in emphasis of their concerns to issues of menstrual hygiene and building healthy relationships with members of the opposite sex. This means that participants at reproductive health sessions should be separated into groups so that the peculiar needs of each age group will be addressed. The next programme of this nature will incorporate these principles and ascertain whether the information needs of the adolescents will be met thereby.

This study provides enough justification for incorporating sexuality education into religious activities. Parents, guardians, health educators, religious and other organisations, and the general public should be made aware of the importance of sexuality education for young people, thereby breaking away from ignorance, myths and misconceptions about sexuality and reproductive health. 


\section{REFERENCES}

1. Zeidenstein S and Moore K. Learning about Sexuality: A Practical Beginning. New York: $\quad \mathrm{T}$ h e Population Council, International Women's Health Coalition, 1996.

2. The Guardian Sunday, January 27, 2002.

3. Adjahoto EO, Hodonou KA, de Souza AD, Tete $\mathrm{VK}$ and Baeta S. Teenage knowledge about sex. Sante 2000; 10(3): 195-199.

4. Bibby C. Sex Education: A Guide for Parents, Teachers and Youth Leaders. 2nd Edition. London: Macmillan \& Co. Ltd., 1951.

5. Jacknik M, Isberner F, Gumerman S, Hayworth $\mathrm{R}$ and Braunling-McMorrow D. OCTOPUSa church-based sex education program for teens and parents. Adolescence 1984; 19(76): 757-763.

6. Coyne-Beasley $\mathrm{T}$ and Schoenbach VJ. The African-American Church: a potential forum for adolescent comprehensive sexuality education. $J$ Adolesc Health 2000; 26(4): 289-294.

7. Marsiglio $\mathrm{W}$ and Mott FL. The impact of sex education on sexual activity, contraceptive use and premarital pregnancy among American teenagers. Fam Plann Persp 1986; 18(4): 151-162.

8. Miller L and Gur M. Religiousness and sexual responsibility in adolescent girls. I Adolesc Health 2002;31(5): 401-406.

9. Mercer R, Ramos S, Szulik D and Zamberlin N. The need for youth-oriented policies and programmes on responsible sexuality in Argentina. Reprod Health Matters 2001; 9(17): 184-191.

10. Smyth F. Cultural constraints on the delivery of HIV/AIDS prevention in Ireland. Soc Sci Med 1998; 46(6): 661-672.
Unmet Need for Sexuality Education

11. Hudelson PM. Qualitative Research for Health Programmes. Geneva: World Health Organisation, Division of Mental Health, WHO / MNH / PSF /94.3, 1994.

12. Smith JA. Beyond the divide between cognition and discourse using interpretative phenomenological analysis in health psychology. Psychol Health 1996; 11:261-271.

13. Berk L. Child Development. 4th Edition. London: Allyn and Bacon, 1997.

14. Piaget J. The Equilibrium of Cognitive Structures: The Central Problem of Intellectual Development. Chicago: University of Chicago Press, 1985.

15. Drake P. Addressing the developmental needs of pregnant adolescents. J Obstet Gynaecol Neonat Nurs 1996; 25: 518-524.

16. Dell D. In: Stotland NL and Steward DE (Eds.). Adolescent Pregnancy in Psychological Aspects of Women's Health Care: The Interface between Psychiatry and Obstetrics and Gynaecology. 2nd edition. Washington DC: American Psychiatric Press, 2001.

17. Walraven G, Ekpo G, Colemen R, Scherf C, Morison L and Harlow SD. Menstrual disorders in rural Gambia. Stud Fam Plann 2002; 33(3): 261268.

18. Abioye-Kuteyi EA. Menstrual knowledge and practices amongst secondary school girls in Ile Ife, Nigeria. J Reprod Soc Health 2000; 120(1): 2326.

19. Simes MR and Berg DH. Surreptitious learning: menarche and menstrual product advertisements. Health Care Women Inter 2000; 22(5): 455 .

20. Garg S, Sharma N and Sahay R. Socio-cultural aspects of menstruation in an urban slum in Delhi, India. Reprod Health Matters 2001; 9(17): 16-25. 